\title{
Conference on Differential Geometry and Partial Differential Equations Brasília, May 24-28, 2010
}

On May 24-28, 2010, the Department of Mathematics of the University of Brasília hosted the Conference on Differential Geometry and Partial Differential Equations. The conference was held on the occasion of Professor Keti Tenenblat's 65-th birthday in recognition of her contribution to the interaction between differential geometry and partial differential equations.

Keti Tenenblat is one of the most active Brazilian researchers in differential geometry, whose high-level scientific work has been documented by her extensive and consistent list of relevant publications, including books and research papers in scientific journals. She completed her $\mathrm{PhD}$ at the "Instituto de Matematica Pura e Aplicada"(IMPA) in Brazil, under the guidance of Manfredo Perdigão do Carmo. During her postdoctoral program, under the supervision of S.S. Chern at the University of California, Berkeley, she started her study of the interplay between differential geometry and differential equations. Later she held visiting positions at several universities and research centers, including Yale University, MSRI Berkeley, Institute of Theoretical Physics in Santa Barbara, IMA Minnesota, University of Montreal, McGill University, CRM Montreal.

Her prestige in the Brazilian and in the international scientific community, together with her dynamism, has demanded her collaboration on various scientific activities. She served as President of the Brazilian Mathematical Society in 1992-1993, and also as Chief Editor of the Society's journal, "Matemática Contemporânea", during the period 1991-2010. She became a member of the Editorial Board of Results in Mathematics, as well as a reviewer of a large number of international journals. In recognition of her work, for several years, she was nominated by the Brazilian mathematical community as Coordinator of Mathematics, and as member of the Advisory Committees of the two main Brazilian scientific agencies, namely of the Ministry of Education and of the Ministry of Science and Technology.

Keti Tenenblat is a member of the Brazilian Academy of Sciences and of the Academy of Sciences for the Developing World (TWAS). In 1996, she was 
awarded, by the President of Brazil, the "National Order of Scientific Merit" in recognition of her contributions to the development of science in Brazil. In 2005, she was honored with the title of Professor Emerita of the University of Brasília.

The conference on the occasion of her 65-th birthday took place in Brasília, it was attended by 95 participants, including 14 from abroad. The presence of so many of her students and collaborators was impressive. The conference lectures were given by invited Brazilian and foreign speakers, and the presented research results focused on Differential Geometry and Partial Differential Equations.

Manfredo Perdigão do Carmo opened the week with a nice talk on "Some recent developments of a Hopf theorem". It was a pleasant week which included 31 invited lectures, an honoring ceremony for Keti Tenenblat, a nice boat tour on Paranoá Lake, and a birthday dinner party. The meeting was an opportunity for scientific interaction among the participants and an occasion to appreciate the importance of Keti Tenenblat's academic-scientific trajectory. At the end of this volume there is a list of the conference participants, and also a list of the lectures and posters.

We gratefully acknowledge the financial support for the conference from the following institutions:

- Coordenação de Aperfeiçoamento de Pessoal de Nível Superior (CAPES),

- Conselho Nacional de Desenvolvimento Científico e Tecnológico (CNPq),

- Sociedade Brasileira de Matemática (SBM),

- Instituto Nacional de Ciência e Tecnologia de Matemática (INCTMat),

- Universidade de Brasília (UnB),

- Centro de Seleção e de Promoção de Eventos (CespeUnB),

- Fundação de Empreendimentos Científicos e Tecnológicos (FINATEC),

- Fundação Carlos Chagas Filho de Amparo à Pesquisa do Estado do Rio de Janeiro (FAPERJ).

In particular, we would like to thank professor ChangYu Xia for leading the Scientific Committee, professor Kellcio Oliveira Araújo for the support with the logistics and the local organization of the Conference, and professor Jacob Palis for his important collaboration with the event.

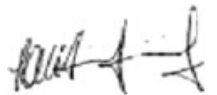

Luciana Maria Dias de Ávila Rodrigues Organizing Committee

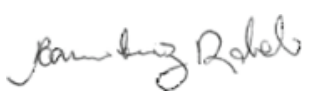

Mauro Luiz Rabelo Organizing Committee 